\title{
A RANDOMIZED, CONTROLLED TRIAL OF TOTAL KNEE REPLACEMENT
}

${ }^{1}$ Dr Waheed Sardar, ${ }^{2}$ Dr Zill e Rehman, ${ }^{3}$ Dr Aniqa Khan

${ }^{1}$ MBBS, Sahiwal Medical College, Sahiwal.

${ }^{2}$ MBBS, Akhtar Saeed Medical and Dental College, Lahore.

${ }^{3}$ MBBS, Quaid e Azam Medical College, Bahawalpur.

\begin{tabular}{|l|l||}
\hline Article Received: March 2020 Accepted: April 2020 Published: May 2020 \\
\hline \hline Abstract: \\
In United States, the number of total knee replacements has been increased drastically from 31.2 per 100,000 \\
person-years. Approximately 670,000 total knee replacements were conducted in 2012 in United States only. \\
With the increase of average age there is expected increase in the number of total knee replacements, which \\
points toward future economic burden. \\
The results of current study has shown that non-surgical treatment followed by total knee replacement therapy \\
are more favorable as compared to nonsurgical treatment alone with pain killers and improving quality of life \\
12 months in patients with moderate-to-severe knee osteoarthritis who are eligible for unilateral total knee \\
replacement. While total knee replacement is linked with a greater number of serious adverse problems and \\
participants who were assigned to get nonsurgical treatment alone were not underwent total knee replacement \\
before the 12-month follow-up and clinically well improvements. \\
\hline
\end{tabular}

Corresponding author:

Dr. Waheed Sardar,

MBBS, Sahiwal Medical College, Sahiwal. 


\section{INTRODUCTION:}

For end stage knee osteoarthritis, the considered effective treatment is total knee replacement. [1]

In United States, the number of total knee replacements has been increased drastically from 31.2 per 100,000 person-years. [2] Approximately 670,000 total knee replacements were conducted in 2012 in United States only. [3] With the increase of average age there is expected increase in the number of total knee replacements [4] which points toward future economic burden.

Recent researches have recommended that nonsurgical treatment of knee osteoarthritis has moderate effectiveness. [5] Such literature encourages the early use of nonsurgical treatment.

The available clinical guidelines and evidence suggest a core treatment program that contains of exercise, education, dietary advice, biomechanical interventions such as insoles, and pharmacologic treatment. [6]

This randomized controlled trial including patients with knee osteoarthritis who were eligible for unilateral total knee replacement, to investigate whether total knee replacement followed by a 12 week nonsurgical-treatment program that consists of exercise, education, dietary advice, use of insoles, and pain medication provides greater pain relief and improvement in function and quality of life than does nonsurgical treatment alone.

\section{METHODS:}

It was a randomized controlled trial. 120 participants were recruited into the study after following the inclusion criteria. According to the Kellgren-Lawrence scale, participants with more than $>2$ score indicating definite osteoarthritis who were eligible for total knee replacement were recruited into the study. The exclusion criteria were containing a need for bilateral total knee replacement, previous total replacement of the same knee, and knee pain during the previous. The randomly assigned participants had to undergo total knee replacement followed by 12 weeks of nonsurgical treatment. According to standard methods12 for insertion of a total cemented prosthesis with patellar resurfacing the total knee replacement was performed. The 12-week nonsurgical-treatment program contained of five interventions: exercise, education, dietary advice, use of insoles, and pain medication. The two groups of total knee replacement were performed in separately but identically, at the same facility, by specially trained physiotherapists and dietitians to ensure proper standardization and to reduce the number of crossovers.
Literature has shown more effectiveness in nonsurgical treatment in a population of patients with knee osteoarthritis of a severity similar to that seen in the study participants [7]

\section{Exercise}

Participants who met the inclusion criteria for total knee replacement were introduced for neuromuscular training program which previously had shown more feasible to patients suffering from moderate to severe knee osteoarthritis. The training program was consisted of 1 hour, group based and twice a week for 12 weeks. The aim of the exercise program was rehabilitation mainly focused on neutral, functional alignment of the legs by building compensatory functional stability and improving sensorimotor control [8] [9]. Patients were analyzed individually to evaluate the exercise quality in which Neutral, dynamic alignment was emphasized.

Pain level was used to guide progression [10].

Education

1-hour educational session was about detail discussion on disease characteristics, treatments, and self-help strategies. The sessions actively engaged patients in the treatment of their knee osteoarthritis.

\section{Dietary Advice}

Participants who were having BMI more than 25 were added into dietary weight loss program which contains of 30 to 60 minutes per session. The main goal of the program was to lwer the body weight by at least 5\%. [11] After the initiation of the nonsurgical treatment a dietitian had communicated thorough telephone to support adherence for at least 30 minutes.

Insoles

The patients received individually fitted, full length insoles with medial arch support.

Pain Medication

if an orthopedic surgeon considered it to be necessary for participation in the exercise program medications were given to the patients. A prescription (reassessed every 3 weeks) was provided for acetaminophen, ibuprofen, and pantoprazole, to be used as needed.

\section{RESULTS:}

Total 80 participants were recruited into the study. A 12 month follow up assessment was completed by $98 \%$ of participants of nonsurgical-treatment group and $91 \%$ of total knee replacement group. $24 \%$ had total knee replacement before the 12 month of follow up in the non-surgical treatment group. Whereas in the non-surgical group $28 \%$ had 
total knee replacement before the 12 month follow up. In the total knee replacement group 3\% manifested to avoid total knee replacement therapy and underwent only non-surgical treatment. The mean follow-up time after the initiation of nonsurgical treatment was 12.4 months in the nonsurgical-treatment group and 12.1 months in the total-knee-replacement group.

\section{DISCUSSION:}

The study has showed that total knee replacement followed by nonsurgical treatment is more efficacious than nonsurgical treatment alone in providing pain relief and improving function and quality of life after 12 months in patients with knee osteoarthritis who are eligible for unilateral total knee replacement. Participants who underwent total knee replacement had faced some serious adverse events which need some clinically relevant improvements in both total knee replacement and non-surgical group. An extensive literature needed on the effectiveness of total knee replacement therapy before its wide use. [13] Both groups in our study had substantial improvement with respect to most outcomes, and only $28 \%$ of the patients who were assigned to receive nonsurgical treatment alone underwent total knee replacement in the following year. Previous studies are in favor of non-surgical treatment for those patients suffering from moderate to severe knee osteoarthritis who are even eligible for total knee replacement. [14] Those participants who had followed a supervised exercise before undergoing the surgery have reported fast post-operative recovery. [15]

The study has some limitations. It has been comprehended that to some extent surgery and nonsurgical treatments are linked with placebo effects. [16] These findings may over take the effects characterized to specific treatments and particularly in surgery.

The scores on the KOOS pain subscale that were obtained before surgery were similar to those obtained in previous studies of total knee replacement and indicated mildto-severe pain during activities, but it is not known whether our results are generalizable to patients with more severe pain. [18] [19] The intensity of nonsurgical treatment may have differed between groups owing to differences in clinical status at the time treatment was initiated. However, the intervention was standardized and administered in both groups by the same physiotherapists and dietitians. Since all patients received multimodal nonsurgical treatment, it is not possible to separate the effects of the individual modes of treatment. [22, 23] The combination of nonsurgical treatments that we administered complies with international recommendations on the treatment of knee osteoarthritis, which increases the generalizability of the results. [24] [25]

\section{CONCLUSION:}

The results of current study has shown that nonsurgical treatment followed by total knee replacement therapy are more favorable as compared to nonsurgical treatment alone with pain killers and improving quality of life 12 months in patients with moderate-to-severe knee osteoarthritis who are eligible for unilateral total knee replacement. While total knee replacement is linked with more number of serious adverse problems and participants who were assigned to get nonsurgical treatment alone were not underwent total knee replacement before the 12-month followup and clinically well improvements.

\section{REFERENCES:}

1. Carr AJ, Robertsson O, Graves S, et al. Knee replacement. Lancet 2012;379:1331- 40.

2. Singh JA, Vessely MB, Harmsen WS, et al. A population-based study of trends in the use of total hip and total knee arthroplasty, 19692008. Mayo Clin Proc 2010; 85:898-904.

3. Agency for Healthcare Research and Quality. Healthcare Cost and Utilization Project database. $2012 \quad$ (http://hcupnet .ahrq.gov/HCUPnet.jsp.)

4. Kurtz S, Ong K, Lau E, Mowat F, Halpern M. Projections of primary and revision hip and knee arthroplasty in the United States from 2005 to 2030. J Bone Joint Surg Am 2007;89:780-5.

5. Lim HC, Adie S, Naylor JM, Harris IA. Randomised trial support for orthopaedic surgical procedures. PLoS One 2014;9(6): e96745.

6. Fernandes L, Hagen KB, Bijlsma JW, et al. EULAR recommendations for the nonpharmacological core management of hip and knee osteoarthritis. Ann Rheum Dis 2013;72:1125-35.

7. McAlindon TE, Bannuru RR, Sullivan MC, et al. OARSI guidelines for the nonsurgical management of knee osteoarthritis. Osteoarthritis Cartilage 2014;22: 363-88.

8. Nelson AE, Allen KD, Golightly YM, Goode AP, Jordan JM. A systematic review of recommendations and guidelines for the management of osteoarthritis: the Chronic Osteoarthritis Management Initiative of the U.S. Bone and Joint Initiative. Semin Arthritis Rheum 2014;43:701- 12.

9. Skou ST, Roos EM, Laursen MB, et al. Total knee replacement plus physical and medical therapy or treatment with physical and medical therapy alone: a randomised controlled trial in patients with knee osteoarthritis (the MEDIC- 
study). BMC Musculoskelet Disord 2012;13:67.

10. Moher D, Hopewell S, Schulz KF, et al. CONSORT 2010 explanation and elaboration: updated guidelines for reporting parallel group randomised trials. BMJ 2010;340:c869.

11. Schiphof D, de Klerk BM, Kerkhof HJ, et al. Impact of different descriptions of the Kellgren and Lawrence classification criteria on the diagnosis of knee osteoarthritis. Ann Rheum Dis 2011;70:1422-7.

12. Endres S. High-flexion versus conventional total knee arthroplasty: a 5-year study. J Orthop Surg (Hong Kong) 2011; 19:226-9.

13. Skou ST, Rasmussen S, Laursen MB, et al. The efficacy of 12 weeks non-surgical treatment for patients not eligible for total knee replacement: a randomized controlled trial with 1-year follow-up. Osteoarthritis Cartilage 2015;23:1465-75.

14. Ageberg E, Link A, Roos EM. Feasibility of neuromuscular training in patients with severe hip or knee OA: the individualized goal-based NEMEX-TJR training program. BMC Musculoskelet Disord 2010; 11:126.

15. Ageberg E, Roos EM. Neuromuscular exercise as treatment of degenerative knee disease. Exerc Sport Sci Rev 2015;43:14-22.

16. Christensen R, Bartels EM, Astrup A, Bliddal $H$. Effect of weight reduction in obese patients diagnosed with knee osteoarthritis: a systematic review and metaanalysis. Ann Rheum Dis 2007;66:433-9.

17. Miller WR, Rollnick S. Motivational interviewing: preparing people for change. New York: Guilford Press, 2002.

18. Ageberg E, Bennell KL, Hunt MA, Simic M, Roos EM, Creaby MW. Validity and interrater reliability of medio-lateral knee motion observed during a singlelimb mini squat. BMC Musculoskelet Disord 2010;11:265.

19. Roos EM, Roos HP, Lohmander LS, Ekdahl C, Beynnon BD. Knee Injury and Osteoarthritis Outcome Score (KOOS) - development of a self-administered outcome measure. J Orthop Sports Phys Ther 1998;28:88-96. Gossec L, Paternotte S, Maillefert JF, et al. The role of pain and functional impairment in the decision to recommend total joint replacement in hip and knee osteoarthritis: an international crosssectional study of 1909 patients: report of the OARSI-OMERACT Task Force on total joint replacement. Osteoarthritis Cartilage 2011;19:147-54.

20. Roos EM, Toksvig-Larsen S. Knee Injury and Osteoarthritis Outcome Score (KOOS) validation and comparison to the WOMAC in total knee replacement. Health Qual Life Outcomes 2003;1:17.
21. Collins NJ, Misra D, Felson DT, Crossley KM, Roos EM. Measures of knee function: International Knee Documentation Committee (IKDC) subjective knee evaluation form, Knee Injury and Osteoarthritis Outcome Score (KOOS), Knee Injury and Osteoarthritis Outcome Score Physical Function Short Form (KOOS-PS), Knee Outcome Survey Activities of Daily Living Scale (KOS-ADL), Lysholm Knee Scoring Scale, Oxford Knee Score (OKS), Western Ontario and McMaster Universities Osteoarthritis Index (WOMAC), Activity Rating Scale (ARS), and Tegner Activity Score (TAS). Arthritis Care Res (Hoboken) 2011; 63:Suppl 11:S208-S228.

22. Roos EM, Engelhart L, Ranstam J, et al. ICRS recommendation document: patientreported outcome instruments for use in patients with articular cartilage defects. Cartilage 2011;2:122-36.

23. Podsiadlo D, Richardson S. The timed "up \& go": a test of basic functional mobility for frail elderly persons. J Am Geriatr Soc 1991;39:142-8. White DK, Zhang Y, Niu J, et al. Do worsening knee radiographs mean greater chances of severe functional limitation? Arthritis Care Res (Hoboken) 2010; 62:14339.

24. Szende A, Williams A. Measuring selfreported population health: an international perspective based on EQ-5D. Budapest, Hungary: SpringMed, 2004. 26. WittrupJensen KU, Lauridsen J, Gudex C, Pedersen KM. Generation of a Danish TTO value set for EQ-5D health states. Scand J Public Health 2009;37:459-66. 27. What is a serious adverse event? Silver Spring, MD: Food and Drug Administration,

2014 (http://www.fda.gov/Safety/

25. MedWatch/HowToReport/ucm053087.htm). 28. Skou ST, Roos EM, Laursen MB, et al. Statistical analysis plan (SAP) for MEDIC: total knee replacement plus physical and medical therapy or treatment with physical and medical therapy alone: a randomised controlled trial in patients with knee osteoarthritis (the MEDIC-study). Aalborg, Denmark: Aalborg University Hospital, 2014 (http://vbn.aau.dk/da/publications/ 